\title{
Sustainability Learning Labs in Small Island Developing States: A Case Study of the Seychelles
}

\section{Journal Article}

\section{Author(s):}

Krütli, Pius; Pohl, Christian; Stauffacher, Michael (1)

Publication date:

2018

Permanent link:

https://doi.org/10.3929/ethz-b-000292870

Rights / license:

Creative Commons Attribution 3.0 Unported

Originally published in:

GAIA - Ecological Perspectives for Science and Society 27(Supplement 1), https://doi.org/10.14512/gaia.27.S1.11 


\section{Sustainability Learning Labs in Small Island Developing States}

\section{A Case Study of the Seychelles}

Pius Krütli, Christian Pohl, Michael Stauffacher
Sustainability Learning Labs in Small Island Developing States. A Case Study of the Seychelles GAIA 27/S1 (2018): $46-51$

\begin{abstract}
In the discussion of real-world laboratories, the teaching component is widely lacking. We address this by introducing a prototype of a sustainability learning lab (SLL) in the global South using a case study of the Seychelles as an example. In 2015 the Transdisciplinarity Lab (TdLab) of ETH Zurich initiated a long-term collaboration with the University of Seychelles (UniSey) and the Ministry of Environment, Energy and Climate Change (MEECC). Teaching activities include transdisciplinary case studies (tdCS) for students from UniSey and ETH, alternated with courses for UniSey only. BSc and MSc theses as well as internships complement these. In 2016 the TdLab, UniSey and MEECC jointly decided to focus on solid waste in a tdCS that engaged $18 \mathrm{ETH}$ and 18 UniSey students with diverse backgrounds. This collaborative approach in a real-world setting with students from different cultures and engaging with a broad range of stakeholders is promising. Students managed to bring novel observations and insights to the surface. Thus, students both profit from this learning platform and also contribute substantially to the further development of the SLL.
\end{abstract}

\section{Keywords}

real-world laboratory, Small Island Developing States, sustainability learning lab, teaching formats,

transdisciplinarity
The teaching component is widely lacking in the discussion of real-world laboratories. We introduce a sustainability learning lab, where students both profit from this platform and also contribute to the success of the lab.

\footnotetext{
$T$
} he objective of the following article is to discuss an aspect that we suggest should be a component of a "Reallabor" (realworld laboratory, RwL), namely teaching activities. This seems timely, because only very few articles discuss the role of teaching in the context of sustainability transformation (e.g., Trencher et al. 2016) yet not specifically in connection with RwLs. This is surprising given the increasing attention by researchers in the fields of sustainability science and transdisciplinary research to the RwL concept (Luederitz et al. 2017).

RwLs have emerged as research approaches at the science-society interface and have gained attention among German scholars (e.g., De Flander et al. 2014, Schäpke et al. 2015). RwL projects are described as "hybrids" between scientific object and transformative subject (Wagner and Grunwald 2015). According to Wagner and Grunwald (2015) RwLs have in common that they: are embedded in real-world contexts; include co-design/co-production of knowledge; have a focus on sustainable transformation; are context-specific; allow for reflection and learning; and are sources of changes. The emphasis of their article is on societal learning processes with little reference to education of students.

The notion of transdisciplinarity is also discussed in connection with the still vague concept of RwL. For some scholars it is questionable whether an RwL is substantially different from transdisciplinarity (Jahn and Keil 2016). For others, transdisciplinarity is seen as the scientific vehicle of an RwL (Wagner and Grunwald 2015). We define transdisciplinarity as a scientific approach in research and teaching that 1 . starts from a real-world problem, 2. goes beyond interdisciplinarity, as it also involves actors from outside academia in a functional way, meaning according to the substantive needs of the project, 3 . meets the needs of realms prac-
Contact: Dr. Pius Krütli | Tel.: +41 446326324 |

E-Mail: pius.kruetli@usys.ethz.ch

Dr.Christian Pohl | E-Mail: christian.pohl@env.ethz.ch

Prof. Dr. Michael Stauffacher |

E-Mail: michael.stauffacher@usys.ethz.ch all: ETH Zurich | Department of Environmental Systems Science (D-USYS) | Institute for Environmental Decisions | USYS TdLab | Universitätstr. 22 | 8092 Zurich | Switzerland

(C) 2018 P. Krütli et al.; licensee oekom verlag. This is an Open Access article distributed under the terms of the Creative Commons Attribution License (http://creativecommons.org/licenses/by/3.0), which permits unrestricted use, distribution, and reproduction in any medium, provided the original work is properly cited. 


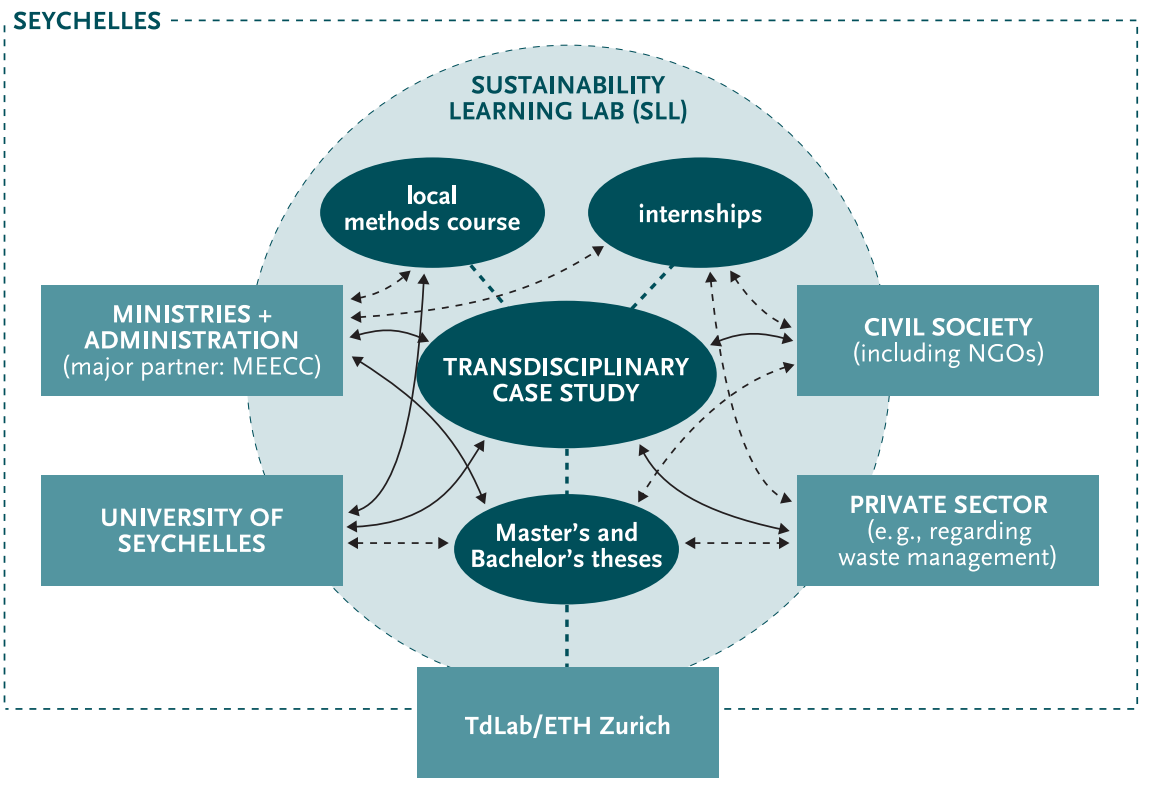

FIGURE 1: The structure of the sustainability learning lab includes four teaching components (ellipses) in the Seychelles (structurally linked to TdLab/ETH). Boxes indicate major partners. Continuous arrows indicate well established collaborations, whilst dotted arrows indicate potential collaborations.

In the following, we introduce and discuss a prototype of a sustainability learning lab (SLL) that we offer in the global South. We focus on Small Island Developing States (SIDS ${ }^{1}$ ) and use the Seychelles as a case study. We use the term "lab" metaphorically in the broad sense of an inspiring and creative learning space where people (e. g., from university, civil society, government) meet, share ideas, and create new knowledge in the context of sustainability.

tice as well as science, and 4. is intended to create change. This means, transdisciplinarity is not identical to an RwL but is rather a scientific means to propel it. While teaching is a widely absent component in discussions about RwLs (for an exception see, e.g., Parodi et al. 2016, Singer-Brodowski et al. 2018, in this issue), teaching has been important for many years in transdisciplinary activities (e.g., at ETH Zurich, Leuphana Lüneburg and elsewhere).

Teaching in real-world settings goes beyond the sender-receiver model, as Stauffacher and colleagues (2006) pointed out. Realworld problems in the context of sustainability are complex and focus on uncertain and contested issues and can thus not be conveyed in a traditional lecture format. This is acknowledged by many others in the field of sustainability education, but most of them design real-world learning environments specifically for students (e.g., Brundiers et al. 2010). However, RwLs actually already offer a perfect setting that allows integration of transdisciplinary research with higher education for sustainable development. Accordingly, students have to take an active part in a "community of practice" (Lave and Wenger 1991) where they temporarily engage with scientists and practitioners to investigate a specific topic (Stauffacher et al. 2006) and produce scientifically robust and practically relevant knowledge. In line with this a few scholars have more recently pointed out the potential of (sustainability) teaching and the role of students as social change agents in real-world sustainability transformation processes (McCormick and Kiss 2015, Rosenberg Daneri et al. 2015, Trencher et al. 2016).

We think teaching activities regarding sustainability offer considerable potential especially in developing countries. Capacity building with respect to transformative sustainability research is timely here and much needed to adequately address the considerable challenges of global sustainability. We consider competence fields such as communication, reflection, problem-framing, research in the real world, and solution imagining as must for our students (see also Wiek et al. 2011, Pearce et al. forthcoming).

\section{Establishing a Sustainability Learning Lab in the Seychelles}

SIDS are facing particular challenges: they are small, remote and isolated; have limited resources and small domestic markets; are exposed and highly vulnerable; have limited capacities; and may have fragile cultural and political systems (Briguglio 1995, United Nations 2014). This makes SIDS ideal learning localities, potential experimental fields for innovations, and cells for transformation initiatives and sustainability research.

The Seychelles, located in the southern part of the Indian Ocean, is a small state of 450 square kilometers land mass spread over some 115 islands within a sea area of 1.4 million square kilometers. The archipelago shares most of the other SIDS' challenges like size and isolation from global markets. Furthermore, the Seychelles have limited resources and small domestic markets (93,000 inhabitants); they are exposed and highly vulnerable to effects of climate change; they increasingly face side effects typical of rapidly developing societies; and they have limited capacities for long-term planning and infrastructure management. These challenges, together with cultural (multiple ethnic groups) and political characteristics (the country is undergoing a political transformation following the termination of a four-decade domination by the socialist party), provide excellent opportunities for students to experimentally study and better address sustainability.

Our activities in the Seychelles meticulously follow the principles for transboundary research partnerships as stipulated by the Swiss Commission for Research Partnerships with Developing Countries (KFPE 2012). These stipulations are key for avoiding neocolonialism and are intended to act as a guarantee that services are produced together with and for the community. In 2015

1 https://sustainabledevelopment.un.org/topics/sids 
the Transdisciplinarity Lab (TdLab) of ETH Zurich initiated a collaboration agreement with the University of Seychelles (UniSey) and the Ministry of Environment, Energy and Climate Change (MEECC). Teaching activities include transdisciplinary case studies (tdCS) alternating with methods courses at UniSey, Bachelor's and Master's theses, and internships (figure 1). The tdCS, an elective course for Master's students of ETH Zurich, functions as the structural foundation of the learning lab.

\section{Teaching Formats}

\section{Transdisciplinary Case Study}

The learning objectives of a tdCS include 1 . understanding a case in its context, 2. knowledge application in the real world, 3. independence in managing research activities, 4. use of transdisciplinary methods, 5 . working in intercultural teams, as well as 6 . adapting to foreign social, economic, cultural and political settings. In addition to these learning objectives, the tdCS also aims to meet the needs of its practice partners. This was achieved firstly by joint problem framing, which is fundamental to transdisciplinary approaches (Pohl et al. 2017): for the tdCS during 2016, TdLab, UniSey and MEECC jointly decided to focus on solid waste management which is a major problem in the Seychelles (box 1). Moreover, it was achieved by mid-term validation through local waste experts, by working closely with local government, private sector, community, and by research collaborations with students at the UniSey.

The tdCS 2016 engaged 18 ETH Master's students with diverse scientific backgrounds and foci such as environmental, agricultural, engineering, and planning sciences. In addition, 18 UniSey environmental Bachelor's students participated. The team conducted the tdCS in two stages:

The tdCS began at ETH in Zurich, where students met each week during the semester. They were engaged in literature review, research plan development, and field preparation. Starting with a wicked problem (solid waste management in the Seychelles), students quickly familiarized themselves with the given problem by understanding the context, implications, and people involved. Students split up into smaller research groups, in which they would each tackle a subtopic (box 1), often in collaboration with others from different disciplines. In these smaller groups, the students created research questions and began to design their studies. About halfway into this period the ETH students and lecturers engaged in a two-day workshop involving stakeholders from the Seychelles. Its purpose was to validate the on-going work. Before going into the field, the students had to create a detailed research plan, involving the methods they wanted to apply, schedules, and stakeholders to interview.

Students were required to take the initiative in the tdCS by organizing themselves and their research, while the lecturers acted as coaches who provided input as needed. Researchers from ETH assisted with expertise on demand. Techniques such as soft
BOX 1: The Problem of Waste in the Seychelles and the Transdisciplinary Case Study (tdCS) Approach

Solid waste is a major issue affecting the Seychelles. Almost all goods need to be imported. Waste increased almost 100 percent in the last 15 years. The current waste management practice is landfilling on reclaimed land. All waste types are deposited on the same landfill. Waste is collected on a daily basis by a private company. There is currently no sorting system at the source. A levy system on cans and PET bottles allow these types of waste, together with scrap metals, to enter the international recycling stream.

The focus of the tdCS was to understand solid waste management in the Seychelles and to provide insights into the reduction of waste to be dumped. To achieve a balance between a comprehensive systemic overview and in-depth work, the study team was split into seven smaller groups. Students worked along an integrated waste management system that distinguishes influencing factors like legal institutions and the phases of the waste cycle (e. g., waste production). Accordingly, students focused on 1. the legal and institutional framework, 2. optimizing recycling markets, 3. material flow analysis of waste streams, 4. environmental impacts of the landfills, 5 . consumer behavior and perspectives on waste, 6 . biowaste to biogas, 7. landfill scenario modelling (for results and further details see Lai et al. 2017).

system methodology (Checkland and Poulter 2010) and design thinking (e.g., Brown and Wyatt 2010) facilitated better understanding of the waste system in the Seychelles and allowed for concise and unambiguous problem statements and research questions. To prepare the field phase, students of ETH paired up at an early stage with students from UniSey via skype, e-mail and phone.

The preparatory phase was followed by three weeks of intensive field research in the Seychelles, a collaborative effort by UniSey and ETH students. The field phase began with a visit to Providence landfill (figure 2) to sensitize the students to the problem at hand. Local waste managers prepared and guided this activity. In addition to daily plenaries, a board of local advisors and experts ${ }^{2}$ met regularly with the student groups to guide their data collecting and report writing throughout the field phase. Experts and stakeholders were actively involved both in shaping the content of the interviews and surveys and by providing data which were processed by students and validated again by local actors at a later stage. Students were exposed to diverse methods of data collection and analysis, including material flow analysis, expert interviews, environmental sampling, surveys, and scenario modelling. Students intensively engaged with a variety of people from government, private sector, and civil society. They conducted about 180 interviews with all relevant stakeholders of the waste management field. Students also took water samples around the Providence dumping site to assess environmental impacts and analyzed them at the lab of Uni-

\footnotetext{
2 Board members are appointed in consultation with the MEECC and represent the MEECC, UniSey, NGOs, the fields of landscape and waste management as well as energy.
} 
Sey under the guidance of local researchers. The typical students' approach was face-to-face interviews both for data collection and validation after processing. Preliminary results were discussed and validated with the advisory board of local experts. Thus, knowledge was co-produced by students and local actors. The sequence of data gathering, analyzing and validating in an unfamiliar context was essential for spurring the learning process of all participants.

The tdCS participants also engaged local media to increase transparency regarding their research progress via newspaper articles and news castings. As the research groups collected data, met stakeholders, and learned about the community, they analyzed and detailed their findings in preliminary reports. The culmination of the tdCS was a public event during which pairs of students from ETH and UniSey presented their findings.

As a follow-up activity, two volunteer students revised and combined students' results in a final report under the guidance of the coaches. It was then revised internally and validated by the local advisory board members. Finally, the report was intensively discussed with the local partners (e.g., Minister of MEECC) and made public to enable stakeholders to benefit from the findings of the study. These activities serve to explore the next steps in the waste management project. A continuation of the activities targeting waste management is already planned for the upcoming tdCS which allows a new cohort of students to study the implementation of findings of the tdCS 2016. The final report (Lai et al. 2017) includes a number of concrete options for improving waste management. An eight-page summary in the format of a newspaper supplement - also prepared by students - informed the broader public.

\section{Local Methods Course}

Alternating between the tdCS of ETH and UniSey, TdLab in collaboration with UniSey offers a local methods course to UniSey students. On the one hand, it provides opportunities for ETH Master's students to engage as tutors. Such a "peer-to-peer" teaching allows ETH students to apply and pass on to UniSey students what they have learned during the tdCS in the previous year, and in turn, learn from them regarding the Seychelles case. On the other hand, UniSey students benefit from a methods course which serves to prepare them for the joint tdCS in the following year. The threeweek course focuses on interdisciplinary collaboration, systems thinking, and sustainability assessment which are hitherto not yet established at UniSey. In terms of sustainability these are crucial elements, as most local graduates will be absorbed by the local job market. The classes include 15 to 20 undergraduate students of different disciplines. A specific focus is given to practical methods application, including case encounter, interviews, workshops, etc.

\section{Master's and Bachelor's Theses}

A third teaching element encompasses Master's and Bachelor's theses. These activities are meant to be complementary to the tdCS and the local methods course. They provide the opportunity to deepen specific aspects. The thesis model includes joint se-

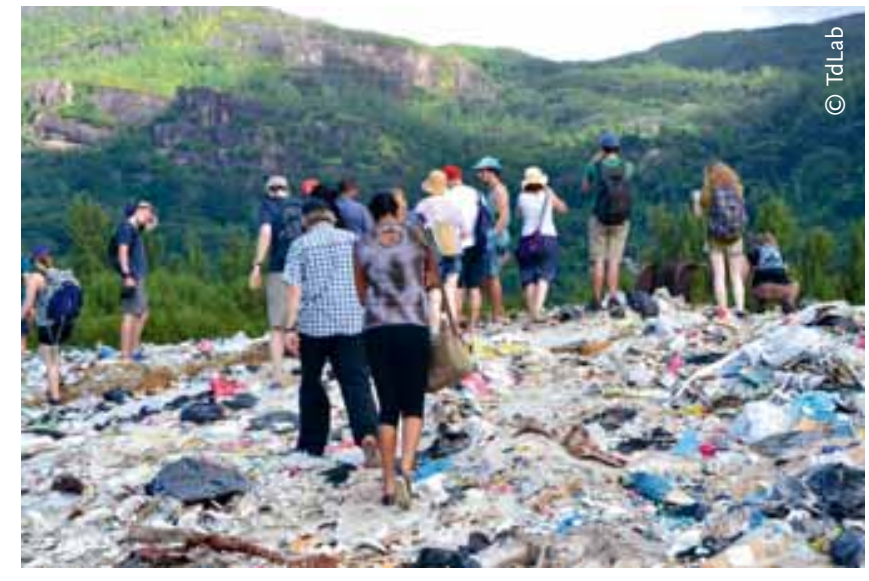

FIGURE 2: Field phase of the transdisciplinary case study. Students from ETH and UniSey experiencing the Providence landfill on Mahé, Seychelles.

lection of the topic and problem framing by students, coaches, and practice partners. The latter two also jointly supervise the theses. Such an approach increases the possibility that findings of the thesis are implemented; it heightens the students' motivation and supports their learning process. A first cohort of ETH students has completed their MSc theses following this model.

\section{Internships}

A final element of our efforts to establish a SLL in the Seychelles are internships. ${ }^{3}$ Students will be given the opportunity to acquire practical experience in a professional field. Internship students are not required to conduct research. For them practical training is prioritized. Internships allow students to contribute to societal problem solving (Rosenberg Daneri et al. 2015), as potential employers like $\mathrm{NGOs}^{4}$ often have a focus on transformation activities.

\section{First Lessons Learnt}

The components of our SLL have proven to work in the local southnorth context. Initial activities were concluded with measurable positive effects. Waste management is given top priority by the decision makers and, as current activities show, the suggestions offered by students seem likely to be followed-up and implemented. Government recently hired two experts who are dedicated and responsible for the waste management. They have banned imports of plastic bags and styrofoam food boxes and are about to introduce a levy system on imported glass bottles. These actions are either a direct result of, or spurred by, the tdCS findings.
3 Internships of four to six months are compulsory components of,
for example, the Environmental Sciences curriculum at ETH Zurich.
4 For an example see Sustainability for Seychelles (S4S): www.s4seychelles.com. 
As indicated by informal feedback, the SLL is an inspiring learning platform (even at its current preliminary stage) not only for students, lecturers/coaches and researchers, but also for a wide range of participants of the local community. It effectively paves the way for the launching of new topics and for their scientific study and evaluation. The knowledge and methodological skills of young, well-educated and top-motivated students, coupled with the expertise and the experience of local actors, are likely to form an important base for future interventions. Students bring to the table not merely their various disciplinary backgrounds and skills, they also provide an outsider perspective. As they are in general free of fixed positions and self-oriented subjective stakes, their creativity is likely to be relatively free from limiting presuppositions. This in turn increases the possibility that findings are adopted by practice as feedback suggest.

Furthermore, this transdisciplinary and intercultural approach allowed peer-to-peer learning and bi-directional capacity building. Evaluation results of the tdCS indicate that students were extremely satisfied with the course as a whole (6.7 for ETH, 6.2 for UniSey students on a 7-point scale, $N=36$ ), and with learning objectives (for ETH students only, $n=18)^{5}$ such as "team-work" (6.9), "stakeholder engagement” (6.6), "self-organization” (6.8). These objectives have been achieved very well, whilst "defining research questions" (5.8), "scientific work" (5.2), and "application of methods" (4.5) were evaluated as fairly good. The latter three somewhat lower ratings may indicate that the students focused more heavily on the other learning objectives as compared to the scientific ones.

However, collaboration and communication between ETH and UniSey students occasionally turned out to be challenging. Collaboration, for example, became partly difficult in the final step of the field phase when ETH students were under much pressure to finalize the final reports. At the same time, they felt obliged to teach their undergraduate colleagues from UniSey to improve their analyzing and writing skills so that they were able to contribute to the written documents. Communication, on the other hand, is per se challenging as students' groups work separately during the semester phase and face-to-face collaboration can only happen once ETH students are in the field. In addition, knowledge levels, cultural behavior, and understanding of work may hinder communication in the beginning of the field phase. All these limitations need to be (better) addressed in the follow-up activities.

The litmus test of the SLL will be to anchor the lab adequately into the local structures and become self-propelled. The SLL is still fueled by ETH TdLab, although it is already well docked to UniSey, to the ministries and government administration and, to some extent, to NGOs and the wider civil society. However, a future well-functioning process needs to be anchored in the curriculum of UniSey and the policy cycle backed by local structures and committed staff.

5 Since the SLL is in development and not yet included in the curriculum of UniSey, UniSey students did not evaluate learning objectives.

6 See also Schäpke et al. (2018, in this issue).

\section{Concluding Discussion}

We presented a preliminary prototype of a SLL in the Seychelles. The SLL is an integrated teaching-research activity which includes four complementary teaching formats (figure 1) and engages in diverse topics and with a variety of local players. It is meant to coproduce new insights about the (solid waste) problem and how it might be tackled and potentially transformed towards more sustainable solutions (Wiek et al. 2012, Schneidewind et al. 2016). The four teaching formats of tdCS, local method course, Master's (ETH) and Bachelor's (UniSey) theses, and internships offer a learning space for knowledge production in the context of sustainability; internships may have a particular function in the implementation stage (Rosenberg Daneri et al. 2015).

Furthermore, the SLL reflects a platform that is embedded in the local context both content-wise by addressing urgent local problems (e.g., the threatening waste accumulation) and via the collaboration with key stakeholders (e.g., the ministries, private sector, and civil society). In this respect, the SLL also reflects a further development of the tdCS at ETH. After a phase using a rather rigid methodological framework for problem framing, analysis, and evaluation of a case (from 2000 until 2006), the tdCS became more research driven due to its link to research projects which resulted in a methodological opening. The current step reflects a further development based on the preceding phases. Here the focus is also on the global South, establishing a long-term collaboration with a case that allows for continuous interaction and more intense and systematic follow-up. This new phase addresses educational needs of a globalized world.

The SLL adds a complementary teaching and learning component to the debate about RwLs. ${ }^{6}$ The SLL has potentially greater leverage in terms of implementation, as it is not merely a subject of scientific investigation but also contributes to the competence of future generations of leaders in the country. However, in contrast to Jahn and Keil (2016) who placed RwLs in the implementation phase, we do not see this as a restriction in our proposed lab. Our activities allow for the generation of all three sorts of knowledge - that is, systems, target and transformation knowledge (ProClim 1997). Generating knowledge is especially important in the global South, as developing countries not only need transformation knowledge but also frequently lack system knowledge. In this respect, our lab represents the first stage of a transformation that creates the needed knowledge (Wiek et al. 2012, Schneidewind et al. 2016). However, implementation activities which lead to societal transformation, as argued by Trencher et al. (2017), may unfold in its full spectrum at a later stage only.

Our experiences indicate that students may bring observations and insights to the surface that neither private consultants nor local experts are able to do. Although the context of the Seychelles is special, we believe the student involvement component has the potential to fuel other approaches, as well, in contexts such as the many ongoing RwLs in Germany (e.g., Schäpke et al. 2015). In fact, we would like to propose that teaching should become an integral part of any RwL, because it is only together with educa- 
tion that the notion can produce what it claims. As transformational change is accomplished by new generations, education of young scholars needs to be firmly integrated into the program. Likewise, our SLL may provide an expansion in the future into a Learning and Research Lab, as both activities are linked. Faculty research is likely to benefit from the real-world setting, teaching may draw from the expertise of faculties, and practice might contribute to and draw from both.

We acknowledge and express our gratitude to all the participants of the tdCS 2016 for their various and valuable contributions, our partners of the UniSey and the MEECC, and all other contributors of the teaching components for providing support to establish the SLL. We thank Sandro Bösch for laying out the figure, Maria Rey for administrative support, and Kjell Törnblom for his language editing. We gratefully acknowledge the helpful comments of two reviewers.

\section{References}

Briguglio, L. 1995. Small Island Developing States and their economic vulnerabilities. World Development 23/9: 1615-1632.

Brown, T., J. Wyatt. 2010. Design thinking for social innovation. Development Outreach 12/1: 29-43.

Brundiers, K., A. Wiek, C. L. Redman. 2010. Real-world learning opportunities in sustainability: From classroom into the real world. International Journal of Sustainability in Higher Education 11/4: 308-324.

Checkland, P., J. Poulter. 2010. Soft systems methodology. In: Systems approaches to managing change: A practical guide. Edited by M. Reynolds, S. Holwell. London: Springer. 191-242.

De Flander, K. et al. 2014. Resilienz und Reallabore als Schlüsselkonzepte urbaner Transformationsforschung. GAIA 23/3: 284-286.

Jahn, T., F. Keil. 2016. Reallabore im Kontext transdisziplinärer Forschung. GAIA 25/4: 247-252.

KFPE (Swiss Commission for Research Partnerships with Developing Countries). 2012. A guide for transboundary research partnerships: 11 principles. Bern: Swiss Academy of Sciences (SAS).

Lai, A., J. Hensley, P. Krütli, M. Stauffacher (Eds.). 2017. Solid waste management in the Seychelles. USYS TdLab Transdisciplinary Case Study 2016. Zurich: ETH Zurich.

Lave, J., E. Wenger. 1991. Situated learning: Legitimate peripheral participation. Cambridge, UK: Cambridge University Press.

Luederitz, C. et al. 2017. Learning through evaluation: A tentative evaluative scheme for sustainability transition experiments. Journal of Cleaner Production 169: 61-76.

McCormick, K., B. Kiss. 2015. Learning through renovations for urban sustainability: The case of the Malmö Innovation Platform. Current Opinion in Environmental Sustainability 16/Suppl. C: 44-50.

Parodi, O. et al. 2016. Das Konzept "Reallabor" schärfen: Ein Zwischenruf des Reallabor 137: KIT findet Stadt. GAIA 25/4: 284-285.

Pearce, B., C. Adler, L. Senn, P. Krütli, M. Stauffacher, C. Pohl. Forthcoming. Making the link between transdisciplinary learning and research. In: The art of collaborative research and collective learning: Transdisciplinary theory, practice and education. Edited by D. Fam, L. Neuhauser, P. Gibbs. London: Springer.

Pohl, C., P. Krütli, M. Stauffacher. 2017. Ten reflective steps for rendering research societally relevant. GAIA 26/1: 43-51.

ProClim. 1997. Research on sustainability and global change: Visions in science policy by Swiss researchers. Bern: Swiss Academy of Sciences (SAS).

Rosenberg Daneri, D., G. Trencher, J. Petersen. 2015. Students as change agents in a town-wide sustainability transformation: The Oberlin Project at Oberlin College. Current Opinion in Environmental Sustainability 16/ Suppl. C: 14-21.

Schäpke, N., M. Singer-Brodowski, F. Stelzer, M. Bergmann, D. J. Lang. 2015 Creating space for change: Real-world laboratories for sustainability transformations: The case of Baden-Württemberg. GAIA 24/4: 281-283.
Schäpke, N. et al. 2018. Jointly experimenting for transformation? Shaping real-world laboratories by comparing them. GAIA 27/S1: 85-96.

Schneidewind, U., M. Singer-Brodowski, K. Augenstein. 2016. Transformative science for sustainability transitions. In: Handbook on sustainability transition and sustainable peace. Edited by H. G. Brauch, Ú. Oswald Spring, J. Grin, J. Scheffran. Cham: Springer International Publishing. 123-136.

Singer-Brodowski, M., R. G. Beecroft, O. Parodi. 2018. Learning in real-world laboratories: A systematic impulse for discussion. GAIA 27/S1: 23-27.

Stauffacher, M., A. I. Walter, D. J. Lang, A. Wiek, R. W. Scholz. 2006. Learning to research environmental problems from a functional socio-cultural constructivism perspective: The transdisciplinary case study approach. International Journal of Sustainability in Higher Education 7/3: 252-275.

Trencher, G. et al. 2016. The role of students in the co-creation of transformational knowledge and sustainability experiments: Experiences from Sweden, Japan and the USA. In: Engaging stakeholders in education for sustainable development at university level. Edited by W. Leal Filho, L. Brandli. Cham: Springer International Publishing. 191-215.

Trencher, G. et al. 2017. Implementing sustainability co-creation between universities and society: A typology-based understanding. Sustainability 9/4: 594.

United Nations. 2014. Trends in sustainable development: Small Island Developing States (SIDS). New York: United Nations.

Wagner, F., A. Grunwald. 2015. Reallabore als Forschungs- und Transformationsinstrument. Die Quadratur des hermeneutischen Zirkels. GAIA 24/1: 26-31.

Wiek, A., B. Ness, P. Schweizer-Ries, F. S. Brand, F. Farioli. 2012. From complex systems analysis to transformational change: A comparative appraisal of sustainability science projects. Sustainability Science 7/1: 5-24

Wiek, A., L. Withycombe, C. L. Redman. 2011. Key competencies in sustainability: A reference framework for academic program development. Sustainability Science 6/2: 203-218

Submitted July 11, 2017; revised version accepted January 14, 2018.

Pius Krütli

Born 1958 in Horw, Switzerland. Doctoral degree at ETH Zurich in 2010. Since 2013 co-director of the Transdisciplinarity Lab of the Department of Environmental Systems Science (USYS TdLab) at ETH Zurich. Research interests: decision-making processes with a special focus on procedural justice, methods and practice of transdisciplinary (research) processes in the context of the global South, justice related to the allocation of scarce resources.

\section{Christian Pohl}

Born 1966 in Windisch, Switzerland. 1999 doctoral degree at ETH Zurich, 2013 habilitation at the University of Bern. 2003 to 2016 co-director of $t d$-net of the Swiss Academies of Arts and Sciences. Since 2013 co-director of the Transdisciplinarity Lab of the Department of Environmental Systems Science (USYS TdLab) at ETH Zurich. Research interest: theory and practice of transdisciplinary research as a means for sustainable development.

\section{Michael Stauffacher}

Born 1965 in Solothurn, Switzerland. 2006 doctoral degree in sociology. Since 2015 Titularprofessor (Adjunct

Professor) at ETH Zurich. Since 2013 co-director of the Transdisciplinarity Lab of the Department of Environmental Systems Science (USYS TdLab) at ETH Zurich.

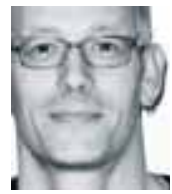

Research interests: contested energy infrastructures, urban development, field experiments, transdisciplinary research. Member of GAIA's Scientific Advisory Board. 